\title{
Change in health knowledge of Bangladeshi children: five years experience
}

\author{
Samir R Nath \\ Research Statistician \\ Research and Evaluation Division, BRAC \\ and \\ A Mushtaque R Chowdhury \\ Director Research, BRAC
}

November 1999

Research and Evaluation Division

75 Mohakhali, Dhaka 1212, Bangladesh 
This article explores the improvement in the level of health knowledge of Bangladeshi children over a five year period 1993-1998. Data were generated from two nationally representative sample surveys covering respectively 2,520 and 3,360 children aged 11-12 years. Six health knowledge items, relevant to life in Bangladesh, were considered. Analyses revealed a significant improvement in the knowledge over the period. However, significant socio-economic variations also persisted in the performance. Rural children improved much faster compared to their urban counterparts. In both the surveys, children's performance varied significantly by items. To equip children with necessary health knowledge this study suggested strengthening health education at primary level in Bangladesh.

Key words: Health knowledge; children; Bangladesh. 


\section{Introduction}

Every month nearly a million children die in the developing world and many millions more live on with ill health and poor growth ${ }^{1}$. A fundamental cause behind this tragedy is poverty. An important cause is their poor knowledge in protecting own health. Recent statistics show that the under five mortality rate in the world has reduced from 193 in 1960 to 86 in $1998^{2}$. However, a wide gap among the countries , also exists.

Basic health knowledge and health care is often recognised as one of the basic human rights $^{3}$. Many declarations and policy papers documented our wish about children to grow up healthy and happy. The 10-point programme, committed by the world's leaders, to protect child rights and improve children's lives include enhancing children's health ${ }^{4}$. The World Declaration on Education for All emphasised the right to all citizens to basic education, which is not only covered by official syllabus of the ' 3 R's' (reading, writing and numeracy) but also focused on learning and skills attained for the purpose of improving quality of lives ${ }^{5}$. It is argued that health content and health skills are vital to enable human beings to survive, to participate fully and to improve quality of their lives 5 .

Children learn basic health knowledge primarily in eariy life through socialisation process; firstly, at home from parents and elders, and then, from other members of the community. Child to child approach to health care is also practised in many traditional societies where children take care of their younger siblings ${ }^{6}$. Children learn necessary health knowledge through schooling too. In some schooling system 
primary health care is a part of curricula. The WHO initiating 'Health promoting school' is an example of conveying healthy lifestyle messages to the students ${ }^{8}$.

In Bangladesh, some three quarters of the primary schooling aged children enrol in schools and nearly 73 percent of them complete the five year cycle of primary education ${ }^{9}$. The education system of the country did not put much emphasis to enrich children with knowledge on essential health and hygiene through schooling. Although, there is a provision of a weekly session on health education in the class routine of the State owned primary schools ${ }^{10}$, it is rarely happens. Moreover, there is no separate textbook for this, rather than putting few sections in the social studies subject. On the other hand, the non-formal primary schools operated by the nongovernment organisations (NGOs) incorporated primary health care issues in the curricula. A recent study confirmed that the students of non-formal schools received more health knowledge than the students of formal schools ${ }^{11}$. Such initiative by NGOs is important, but could not be considered as significant in respect to entire country, because only 8.5 percent of the children enrol in NGO operated schools. The health workers of the government and NGOs provide essential health messages to the population. Programmes delivering information on health care and practices are also regularly transmitted through radio and TV.

Taking data from two national surveys conducted in 1993 and 1998, this article reports the health knowledge of Bangladeshi children on six selected items and examines the change in such knowledge between the two survey periods. 


\section{Methods}

The data used in this paper originated from two nationally representative sample surveys on basic educational attainment of Bangladeshi children aged 11-12 years in 1993 and 1998. The assessment instrument used in the surveys was constructed based on the ideas and concepts generated in the World Conference on Education for All held in Jomtien in $1990^{5}$. The life skills part of the test instrument had six basic questions on general health and public hygiene. These were considered important for children at the current development stage of the country. Assessment was made dichotomously i.e., whether responses were correct or incorrect. Correct answers were defined according to country's cultural context and primary health care system and practice. The questions and their respective correct answers are given in Table 1.

\section{Sampling}

For a precision level of $7 \%$ with $95 \%$ confidence limit, it was estimated that a sample of 196 is necessary to have a single estimate against each of the items ${ }^{12,13}$. Clustersampling approach was followed in the surveys, thus, the sample sizes were doubled to reduce cluster effect on the estimates ${ }^{14}$. The sample size for an estimate thus stood at 392.

The 1993 national survey contained six sub-national surveys, of which five were in the then five rural administrative divisions and one in urban areas. On the other hand, in 1998, eight sub-national surveys were carried out. Of these, six were in six rural administrative divisions (between 1993 and 1998, one division was curved out of the previous form), one in the metropolitan cities and the rest one in the non-metropolitan 
urban areas. A three stage sampling strategy was followed in both the surveys. At the first stage, 30 thanas or sub-districts (pourasava for urban areas) were selected through systematic random sampling technique with probability proportional to size (PPS). At the second stage, one union (ward for urban strata) for each selected thana/pourasava was selected randomly (union is a local government administrative unit with a population of about 22,000). At the third stage, one village (mahallah for urban strata) was randomly selected from each selected union/ward. This means that 30 villages/mahallahs (here called cluster) were selected for each stratum, totalling 180 for the 1993 survey and 240 for the 1998 survey. From each cluster 14 children aged 11-12 years, irrespective of schooling, were selected following a systematic random sampling procedure. Thus, each cluster contained 420 children. The sizes of the samples stood at 2,520 and 3,360 respectively for 1993 and 1998.

The data collection for the first survey was done in February 1993 and the second in October-November 1998. The fieldwork procedure of the surveys were similar in both and details on these are available elsewhere, 15. As strata population varied substantially, appropriate weights were used to calculate the aggregate estimates.

Two methods were used to estimate the reliability of the data, viz., Test-retest method and Kudar-Richardson formula $20(\mathrm{KR} 20)^{16,17,18}$. The former method suggests that the reliability coefficient was 0.96 and 0.93 respectively for 1993 and 1998, and the later method shows it was 0.88 for 1993 and 0.96 for 1998 . All these coefficients are much higher than the satisfactory level of $0.80^{18}$. 


\section{Results}

The percentage of children correctly answered the six questions are presented in Table

2. The level of health knowledge significantly varied by items as the children did not perform equally in the questions. Children's performances in different health knowledge items are described in brief below.

What is a good and simple treatment for diarrhoea?

Nearly three quarters of the interviewed children knew the correct answer of this question in 1993, which rose at 86.1 percent in $1998(\mathrm{p}<0.001)$. Although, a significantly higher proportion of girls, than boys, knew the correct answer in 1993 $(\mathrm{p}<0.01)$, the gap became statistically insignificant in 1998. Among rural children, 72.6 percent knew the correct answer of this question in 1993 , which rose at 84.7 percent in $1998(\mathrm{p}<0.001)$. Among urban children, this rate increased from 90.7 percent in 1993 to 94.5 percent in $1998(\mathrm{p}<0.05)$.

Where should one defecate?

The percentage of children who knew the correct answer of this question increased from 73.8 percent in 1993 to 82.3 percent in $1998(\mathrm{p}<0.001)$. Although, statistically there was no gender variation in the knowledge on this item in 1993, a significant gender gap appeared in favour of boys in $1998(p<0.05)$. The level of knowledge however increased among both boys and girls at national level and in rural areas, it increased only among girls in urban areas. 
How does a child benefit from vaccination?

Only 33.7 percent of the interviewed children knew the correct answer of this question in 1993, which rose at 40 percent in 1998 ( $p<0.001)$. Although there was no difference between the performances of boys and girls in 1993, the girls showed significantly better performance in $1998(p<0.05)$. Over the period, the performance significantly increased among rural and all Bangladesh children $(p<0.001)$.

\section{Which foods help to prevent night blindness?}

The level of knowledge on this item significantly increased from 36.2 percent in 1993 to 48 percent in $1998(\mathrm{p}<0.001)$. No gender variation was observed in the level in any of the surveys. Although the rural children showed significantly better performance over the period $(p<0.001)$, urban children could not do so. Less than a half of the rural children knew the correct answer of this item against over 67 percent of the urban children.

How can water be purified, or made drinkable?

Nearly 55 percent of the children surveyed in 1993 and 67.8 percent of the children surveyed in $1998 \mathrm{knew}$ the correct answer of this question $(\mathrm{p}<0.001)$. Statistically, no variation was observed among the performance of boys and girls in any of the surveys. The improvement over the period was noticed significantly at all levels: rural, urban and national; even when the data were separately analysed for boys and girls $(\mathrm{p}<0.001)$. 
What should be the first aid for someone with a very high temperature (fever)?

The percentage of children who knew the correct answer of this question was 58.5 percent in 1993 and 60.4 percent in 1998. The increase was statistically insignificant, even when the data were separately analysed by area of residence or by sex. Although, there was no gender variation in the knowledge on this item in 1993, a statistically significant gender gap was seen in 1998 in favour of girls $(p<0.05)$.

Table 3 shows that proportion of children knowing correct answer of the health questions increased with the increase in their years of schooling $(p<0.001)$. Some children also had correct answers without having a single year of schooling. Comparing the performance between 1993 and 1998 it can be said that the performance proportionately increased at each grade. The level of health knowledge of children completing a five-year cycle of primary education (which is the official length of primary education in Bangladesh) could also be seen in this Table. For example, after completing the primary cycle of schooling less than a half of the children knew the correct answers of 'benefits of vaccination' and 'prevention of night blindness' in 1993 which rose respectively to nearly 60 percent and 70 percent in 1998. Again, with similar years of schooling, the knowledge on 'water purification' increased by 20 percentage points.

The proportion of children who correctly answered all the six questions was 14.4 percent in 1993, which rose to 18.7 percent in 1998 ( $p<0.001)$ (Table 4). Separate analysis shows that such increase happened only in rural areas, but not in urban areas. Similarly, gender difference in favour of girls was observed in 1998, but not in 1993. 
On average, the children knew 3.3 items in 1993, which increased to 3.8 in 1998 $(\mathrm{p}<0.001)$ (Table 5). The average number of items correctly answered increased in rural areas $(\mathrm{p}<0.001)$, but not in urban areas.

\section{Multivariate analysis}

The above analyses showed that the level of health knowledge of the children increased over time. Logistic regression analysis ${ }^{19}$ was performed to explore the

'increase controlling for socio-economic characteristics of children such as sex, area of residence, child's schooling, mothers education, fathers education and self perceived yearly economic status of household. A total of 35 regression analysis was carried out: seven for all children, 14 for boys and girls separately, and 14 for urban and rural children separately. Table 6 shows the odds ratios of the regression coefficients against year 1998 (1993 as reference year) for each of the questions and all items, controlling for the above characteristics. The findings of the regression analyses show that the children performed significantly better in 1998 than 1993 in all items. However, when the data were analysed separately for boys and girls no significant improvement was seen in the knowledge of 'first aid for high fever'. Again, for urban children, significant improvement was observed only in two items, viz., 'treatment for diarrhoea' and 'water purification'.

Three common observations can be synthesised from the findings of the surveys. Firstly, urban children performed significantly better than rural children in each item $(p<0.001)$. Secondly, children showed outstanding performance in two items, viz., 'treatment for diarrhoea' and place for defecation'; a moderate performance in two, 
viz., 'water for purification' and 'first aid for high fever'; and poor performance in the rest. Thirdly, socio-economic differentials exist in the performance of the children.

\section{Discussion and Conclusion}

This paper explores the improvement in the knowledge of Bangladeshi children on some selected essential health issues. The data for this paper came from two inationally representative sample surveys carried out in 1993 and 1998 on basic educational attainment of children which included six questions on health issues. It is difficult to say how far these questions represent the basket of essential knowledge that the Bangladeshi children need to have. This is because no such basket is available. However, in preparing the assessment instrument for basic education survey, the emphasis was that the instrument covered some essential health knowledge that may help children improve quality of their lives. Again, these six questions partially cover five of the 12 health issues contained in the communication material Facts for Life published jointly by UNICEF, WHO and UNESCO'.

The findings of this study confirmed that not all Bangladeshi children aged 11-12 years were equipped with the 'essential' health knowledge. Significant variation was observed in the level of knowledge by items. The health knowledge also varied according to the socio-economic status of the children. In both the surveys, the interviewed children reported outstanding knowledge regarding 'treatment for diarrhoea' but worst knowledge regarding 'benefits from vaccination'. Although the expanded programme on immunisation was quiet a success in Bangladesh $^{20}$, children do not know adequately about its benefits. The good knowledge seen regarding 
'treatment for diarrhoea' may be attributed to the door-to-door teaching programme on diarrhoeal diseases carried out for millions of mothers in the $1980 \mathrm{~s}^{21}$ and may be another testimony to the cultural incorporation of the knowledge in Bangladesh ${ }^{22}$. Although, no gender variation was found in mean number of correct answers, the girls tended to do significantly better in some of the questions.

Children's health knowledge significantly improved over the period of five and a haif years between 1993 and 1998. Although the rural children showed improved performance in all the questions, the urban children improved only in two. These are 'treatment for diarrhoea' and 'water purification'. The data for the second survey were collected after a widespread flood, which affected about two-thirds of the country including the capital city Dhaka. Messages on these two were reinforced in both rural and urban areas through various social organisations during the flood. The improved performance shown by rural children is because they had very poor health knowledge in 1993. The performance of the rural children in 1998 is even lower than that of the urban children in 1993. This indicates that the rural children will have to do more to reach their urban counterparts. The role of schooling was found significant in raising health knowledge. Primary education has recently been made compulsory in Bangladesh, and the completion rate at primary leve! has also increased considerably creating potentials to deliver health knowledge through existing school system. The experiences of NGOs, such as BRAC's education programme, also corroborate this. 
The main drawback of this study was that it did not elaborately assessed children's knowledge on the health issues. Again, knowledge alone does not guarantee practice. A separate study covering knowledge on more issues relating health and hygiene along with attitude and practice may give better understanding of the situation.

\section{Acknowledgements}

. The surveys were financed by UNICEF, NOVIB of Holland, Sida, UNESCO and BRAC. The Research and Evaluation Division of BRAC shouldered the implementation of the surveys and the Campaign for Popular Education (CAMPE) provided the secretariat for second survey. The authors are grateful to above organisations for their help. The individuals who served in the Advisory Board and the Working Committee for the surveys also deserve acknowledgements. The authors also thank the field investigators and the children interviewed. Thanks are also due to Mr. Hasan Shareef Ahmed for editorial assistance. However, the authors alone are responsible to any inadequacies. 


\section{References}

1. UNICEF, WHO and UNESCO. Facts for Life: A Communication Challenge. P\&LA: Oxfordshire, undated.

2. UNICEF. The State of the World's Children 2000. UNICEF, 2000.

3. WHO and UNICEF. Alma Ata 1978: Primary Health Care. WHO: Geneva, 1978.

4. World Summit for Children. World Declaration on the Survival, Protection and Development of Children. United Nations: New York, 1990.

5. Inter-Agency Commission for the World Conference on Education For All. World Declaration on Education For All. UNICEF: New York, 1990.

6. Otaala B, Myers R, Landers C. Children Caring for Children: New Application of an Old Idea. The Consultation Group on Early Childhood Care and Development: London, 1988.

7. Hawes H, Scotchmer C with Aarons A, Morley D, Young E. Children for Health. Child to Child Trust with UNICEF: London, 1993.

8. Williams P, Weston R, McWhirter J, James E, Moore D, Coulter B, Titheridge C, Halverson J, Potter J. Health Promoting Schools: Lessons from Working Intersectorally with Primary Schools in Australia. Health Education Journal 1996; 55: 300-310. 
9. Chowdhury AMR, Choudhury RK, Nath SR. (Eds.). Hope Not ComplacencyState of Primary Education in Bangladesh 1999. Campaign for Popular Education and University Press Limited: Dhaka, 1999.

10. Primary and Mass Education Division. Education for All: National Plan of Action. Primary and Mass Education Division, Government of the Peoples' Republic of Bangladesh: Dhaka, 1995.

11. Nath SR. Health Knowledge of Rural Bangladeshi Children: Does BRAC's Non-formal Schools Programme have any Impact? Health Education Journal 1999; 58: 26-38.

12. Cochran WG. Sampling Techniques. John Wiley \& Sons: Singapore, 1977.

13. Kalton G. Introduction to Survey Sampling. Sage University Paper Series on Quantitative Applications in the Social Sciences, 07-035. Sage: Newbury Park, CA, 1983.

14. Henderson RH, Sundaresan T. Cluster Sampling to Assess Immunization Coverage: A Review of Experience with a Simplified Sampling Method. Bull World Health Organ 1982; 60(2): 153-260.

15. Nath SR, Mohsin M, Chowdhury AMR. Health Knowledge of Children in Bangladesh: An Exploratory Study. Public Health 1997; 111: 311-315.

16. Gupta SC, Kapoor VK. Fundamentals of Applied Statistics. Sultan Chand \& Son: New Delhi, 1994. 
17. Kuder GF, Richardson MW. The Theory of the Estimation of Test Reliability. Psychometrika 1937; 2: 151-160.

18. Carmines EG, Zeller RA. Reliability and Validity Assessment. Sage University Paper Series on Quantitative Applications in the Social Sciences, 07-017. Sage: Newbury Park, CA, 1979.

19. Menard S. Applied Logistic Regression Analysis. Sage University Paper Series on Quantitative Applications in the Social Sciences, 07-106. Sage: Newbury Park, CA, 1995.

20. Huq $\mathrm{M}$ (Ed.). Near Miracle in Bangladesh. University Press Limited: Dhaka,

21. Chowdhury AMR, Cash RA. A Simple Solution: Teaching Millions to Treat Diarrhoea at Home. University Press Limited: Dhaka, 1996.

22. Chowdhury AMR, Cash RA. Cultural Incorporation of the ORT Message. The Lancet 1993; $341: 1591$. 
Table 1 Question items and their correct answers

\begin{tabular}{|c|c|c|}
\hline \multicolumn{2}{|r|}{ Question items } & Correct answers \\
\hline i) & $\begin{array}{l}\text { What is a good and simple } \\
\text { treatment for diarrhoea? }\end{array}$ & $\begin{array}{l}\text { Giving: packet saline, oral re-hydration } \\
\text { saline, salt-molasses-water saline or home } \\
\text { made saline }\end{array}$ \\
\hline ii) & Where should one defecate? & Slab, pit or sanitary latrine. \\
\hline iii) & $\begin{array}{l}\text { Which foods help to prevent } \\
\text { night blindness? }\end{array}$ & $\begin{array}{l}\text { Green vegetables, yellow fruits, small fish, } \\
\text { or Vitamin A capsule. }\end{array}$ \\
\hline iv) & $\begin{array}{l}\text { How can water be purified, } \\
\text { or made drinkable? }\end{array}$ & $\begin{array}{l}\text { Boiling, using alum, or using water } \\
\text { purification tablet. }\end{array}$ \\
\hline v) & $\begin{array}{l}\text { How does a child benefit } \\
\text { from vaccination? }\end{array}$ & To prevent disease. \\
\hline vi) & $\begin{array}{l}\text { What should be the first aid } \\
\text { for someone with a very high } \\
\text { temperature (fever)? }\end{array}$ & Use cool water to make body/head cool. \\
\hline
\end{tabular}


Table 2 Percentage of 11-12 year old Bangladeshi children correctly answering health knowledge items by area of residence, sex and year

\begin{tabular}{|c|c|c|c|c|c|c|c|c|c|}
\hline \multirow[b]{2}{*}{ Items } & \multicolumn{3}{|c|}{1993} & \multicolumn{3}{|c|}{1998} & \multicolumn{3}{|c|}{ Comparison (1993 v 1998) } \\
\hline & Girls & Boys & Both & Girls & Boys & Both & Girls & Boys & Both \\
\hline \multicolumn{10}{|c|}{ Treatment for diarrhoea } \\
\hline Rural & 75.7 & 69.5 & $72.6 \dagger$ & 84.2 & 85.2 & 84.7 & $\mathrm{p}<0.001$ & $\mathrm{p}<0.001$ & $\mathrm{p}<0.001$ \\
\hline Urban & 90.4 & 91.0 & 90.7 & 94.5 & 94.5 & 94.5 & $\mathrm{p}<0.05$ & ns & $\mathrm{p}<0.05$ \\
\hline All & 77.3 & 71.7 & $74.5 \dagger$ & 85.7 & 86.6 & 86.1 & $\mathrm{p}<0.001$ & $\mathrm{p}<0.001$ & $\mathrm{p}<0.001$ \\
\hline \multicolumn{10}{|c|}{ Place for defecation } \\
\hline Rural & 71.4 & 73.0 & 72.2 & 78.5 & 83.0 & $80.8+$ & $\mathrm{p}<0.001$ & $\mathrm{p}<0.001$ & $\mathrm{p}<0.001$ \\
\hline Urban & 87.7 & 89.6 & 88.6 & 93.1 & 89.2 & $91.2 \ddagger$ & $\mathrm{p}<0.05$ & ns & ns \\
\hline All & 73.1 & 74.6 & 73.8 & 80.7 & 83.9 & $82.3 \ddagger$ & $\mathrm{p}<0.001$ & $\mathrm{p}<0.001$ & $\mathrm{p}<0.001$ \\
\hline \multicolumn{10}{|c|}{ Benefits from vaccination } \\
\hline Rural & 31.3 & 30.6 & 30.9 & 39.2 & 35.9 & 37.5 & $\mathrm{p}<0.001$ & $\mathrm{p}<0.001$ & $\mathrm{p}<0.001$ \\
\hline Urban & 58.4 & 57.7 & 58.1 & 56.3 & 53.0 & 54.6 & ns & ns & ns \\
\hline All & 34.1 & 33.3 & 33.7 & 41.7 & 38.3 & $40.0 \ddagger$ & $\mathrm{p}<0.001$ & $\mathrm{p}<0.001$ & $\mathrm{p}<0.001$ \\
\hline \multicolumn{10}{|c|}{ Prevention for night blindness } \\
\hline Rural & 32.3 & 32.9 & 32.7 & 44.7 & 44.8 & 44.8 & $\mathrm{p}<0.001$ & $\mathrm{p}<0.001$ & $\mathrm{p}<0.001$ \\
\hline Urban & 66.2 & 69.7 & 67.9 & 65.6 & 69.2 & 67.4 & ns & ns & ns \\
\hline All & 35.9 & 36.5 & 36.2 & 47.7 & 48.3 & 48.0 & $\mathrm{p}<0.001$ & $\mathrm{p}<0.001$ & $\mathrm{p}<0.001$ \\
\hline \multicolumn{10}{|c|}{ Water purification } \\
\hline Rural & 53.8 & 51.5 & 52.6 & 64.7 & 65.0 & 64.9 & $\mathrm{p}<0.001$ & $\mathrm{p}<0.001$ & $\mathrm{p}<0.001$ \\
\hline Urban & 71.2 & 73.6 & 72.4 & 83.8 & 86.1 & 85.0 & $\mathrm{p}<0.001$ & $\mathrm{p}<0.001$ & $\mathrm{p}<0.001$ \\
\hline All & 55.6 & 53.6 & 54.6 & 67.5 & 68.1 & 67.8 & $\mathrm{p}<0.001$ & $\mathrm{p}<0.001$ & $\mathrm{p}<0.001$ \\
\hline \multicolumn{10}{|c|}{ First aid for high fever } \\
\hline Rural & 59.1 & 54.9 & $57.0 \ddagger$ & 61.0 & 55.6 & $58.4 \dagger$ & ns & ns & ns \\
\hline Urban & 71.2 & 73.1 & 72.1 & 72.2 & 73.5 & 72.8 & ns & ns & ns \\
\hline All & 60.4 & 56.7 & 58.5 & 62.7 & 58.2 & $60.4 \ddagger$ & ns & ns & ns \\
\hline
\end{tabular}


Table 3 Percentage of 11-12 year old Bangladeshi children correctly answering health question items by years of schooling and year

\begin{tabular}{|c|c|c|c|c|c|c|c|}
\hline \multirow[b]{2}{*}{ Items } & \multicolumn{7}{|c|}{ Years of schooling } \\
\hline & $\overline{\mathrm{Nil}}$ & $\mathrm{I}$ & II & III & IV & $\mathrm{V}$ & $\mathrm{VI}+$ \\
\hline \multicolumn{8}{|l|}{1993} \\
\hline Treatment for diarrhoea & 56.2 & 67.0 & 62.2 & 66.6 & 78.5 & 85.1 & 92.1 \\
\hline Place for defecation & 52.6 & 64.1 & 64.8 & 73.5 & 81.1 & 83.1 & 86.3 \\
\hline Benefit from vaccination & 11.5 & 13.3 & 13.9 & 23.0 & 33.2 & 49.0 & 66.6 \\
\hline Prevention for night blindness & 13.7 & 22.1 & 19.8 & 26.6 & 38.1 & 49.6 & 63.8 \\
\hline Water purification & 34.7 & 43.2 & 37.0 & 45.1 & 57.7 & 65.2 & 80.7 \\
\hline First aid for high fever & 51.6 & 49.4 & 51.3 & 54.6 & 60.3 & 63.4 & 68.9 \\
\hline \multicolumn{8}{|l|}{1998} \\
\hline Treatment for diarrhoea & 67.5 & 76.2 & 84.0 & 89.5 & 91.1 & 94.4 & 95.2 \\
\hline Place for defecation & 65.7 & 73.0 & 80.8 & 80.6 & 88.9 & 90.6 & 93.4 \\
\hline Benefit from vaccination & 18.4 & 23.0 & 33.1 & 31.7 & 45.7 & 59.9 & 74.3 \\
\hline Prevention for night blindness & 20.2 & 31.4 & 43.3 & 41.1 & 56.5 & 69.0 & 76.2 \\
\hline Water purification & 36.3 & 47.7 & 62.1 & 67.3 & 77.3 & 86.3 & 93.8 \\
\hline First aid for high fever & 43.4 & 51.6 & 55.6 & 56.3 & 65.0 & 75.8 & 78.2 \\
\hline
\end{tabular}

Note: According to the increase in years of schooling, statistically significant increase in the knowledge was observed in all 12 cases $(p<0.001)$.

Table 4 Percentage of 11-12 year old Bangladeshi children correctly answering all six items by area of residence, sex and year

\begin{tabular}{|c|c|c|c|c|c|c|c|c|c|}
\hline \multirow{2}{*}{$\begin{array}{l}\text { Area of } \\
\text { Residence }\end{array}$} & \multicolumn{3}{|c|}{1993} & \multicolumn{3}{|c|}{1998} & \multicolumn{3}{|c|}{ Comparison (1993 v 1998) } \\
\hline & Girls & Boys & Both & Girls & Boys & Both & Girls & Boys & Both \\
\hline Rural & 13.0 & 10.5 & 11.7 & 18.1 & 14.3 & $16.2 \dagger$ & $\mathrm{p}<0.001$ & $\mathrm{p}<0.01$ & $\mathrm{p}<0.001$ \\
\hline Urban & 36.1 & 39.8 & 37.9 & 34.4 & 33.1 & 33.8 & ns & ns & ns \\
\hline All & 15.5 & 13.3 & 14.4 & 20.4 & 17.0 & $18.7 \ddagger$ & $\mathrm{p}<0.001$ & $\mathrm{p}<0.001$ & $\mathrm{p}<0.001$ \\
\hline
\end{tabular}

The symbols indicate statistically significant difference in the comparison girls $\mathrm{v}$ boys.

$\dagger$ Significant at $p<0.01$

$\ddagger$ Significant at $p<0.05$

ns $=$ Not significant at $\mathrm{p}=0.05$ 
Table 5 Mean and standard deviation (SD) of the number of question items correctly answering by the Bangladeshi children of age 11-12 year, by sex, area of residence and year

\begin{tabular}{|c|c|c|c|c|c|c|c|}
\hline \multirow{2}{*}{$\begin{array}{l}\text { Residence/ } \\
\text { Year }\end{array}$} & \multicolumn{2}{|c|}{ Girls } & \multicolumn{2}{|c|}{ Boys } & \multicolumn{2}{|c|}{ Both } & \multirow{2}{*}{$\begin{array}{l}\text { Comparison } \\
\text { (Girls v Boys) }\end{array}$} \\
\hline & Mean & SD & Mean & $\mathrm{SD}$ & Mean & $\mathrm{SD}$ & \\
\hline \multicolumn{8}{|l|}{$\overline{A l l}$} \\
\hline 1993 & 3.4 & 1.8 & 3.3 & 1.8 & 3.3 & 1.8 & ns \\
\hline 1998 & 3.9 & 1.7 & 3.8 & 1.7 & 3.8 & 1.7 & ns \\
\hline $\begin{array}{l}\text { Comparison } \\
(1993 \text { v 1998) }\end{array}$ & \multicolumn{2}{|c|}{$\mathrm{p}<0.001$} & \multicolumn{2}{|c|}{$\mathrm{p}<0.001$} & \multicolumn{2}{|c|}{$\mathrm{p}<0.001$} & \\
\hline \multicolumn{8}{|l|}{ Rural } \\
\hline 1993 & 3.2 & 1.8 & 3.1 & 1.8 & 3.2 & 1.8 & ns \\
\hline 1998 & 3.7 & 1.7 & 3.7 & 1.6 & 3.7 & 1.7 & ns \\
\hline $\begin{array}{l}\text { Comparison } \\
(1993 \text { v 1998) }\end{array}$ & \multicolumn{2}{|c|}{$\mathrm{p}<0.001$} & \multicolumn{2}{|c|}{$\mathrm{p}<0.001$} & \multicolumn{2}{|c|}{$p<0.001$} & \\
\hline \multicolumn{8}{|l|}{ Urban } \\
\hline 1993 & 4.5 & 1.6 & 4.5 & 1.6 & 4.5 & 1.6 & ns \\
\hline 1998 & 4.7 & 1.3 & 4.7 & 1.3 & 4.7 & 1.3 & ns \\
\hline $\begin{array}{l}\text { Comparison } \\
(1993 \text { v 1998) }\end{array}$ & \multicolumn{2}{|l|}{ ns } & \multicolumn{2}{|l|}{ ns } & \multicolumn{2}{|c|}{ ns } & \\
\hline
\end{tabular}

ns $=$ not significant at $p=0.05$ 
Table 6 Odds ratios of the logistic regression coefficients against 1998 predicting health knowledge of 11-12 year old Bangladeshi children

\begin{tabular}{|c|c|c|c|c|c|}
\hline \multirow[b]{2}{*}{ Health knowledge items } & \multirow[b]{2}{*}{ All } & \multicolumn{2}{|c|}{ Sex } & \multicolumn{2}{|c|}{ Area } \\
\hline & & Girls & Boys & Rural & Urban \\
\hline Treatment for diarrhoea & $2.40^{*}$ & $1.70^{*}$ & $3.36^{*}$ & $2.41 *$ & $2.44 \dagger$ \\
\hline Place for defecation & $1.84^{*}$ & $1.59^{*}$ & $2.18^{*}$ & $1.86^{*}$ & 1.57 \\
\hline Benefits from vaccination & $1.57^{*}$ & $1.44^{*}$ & $1.75^{*}$ & $1.61^{*}$ & 1.30 \\
\hline Prevention for night blindness & $1.97^{*}$ & $1.75^{*}$ & $2.22 *$ & $2.04 *$ & 1.41 \\
\hline Water purification & $2.02 *$ & $1.73^{*}$ & $2.50 *$ & $1.93^{*}$ & $3.35^{*}$ \\
\hline First aid for high fever & $1.14 \ddagger$ & 1.13 & 1.15 & $1.13 \ddagger$ & 1.25 \\
\hline All items & $1.73^{*}$ & $1.58^{*}$ & $1.95^{*}$ & $1.85^{*}$ & 1.27 \\
\hline
\end{tabular}

Notes:

1. The estimates were calculated by controlling for Sex ( 1 girl, 2 boy); Area ( 1 rural, 2 urban); Child's schooling (0 to 6+ years); Mothers education (0 to $10+$ years); Fathers education ( 0 to $14+$ years); Economic status ( 1 always in deficit, 2 sometimes in deficit, 3 balanced, 4 surplus).

2. The reference category was the children of year 1993. The symbols indicate statistically significant difference in the comparison $1993 \mathrm{v} 1998$.

* Significant at $p<0.001$

$\dagger$ Significant at $p<0.01$

$\ddagger$ Significant at $p<0.05$ 